\title{
Reasoning for adherence to aseptic practices in the operating room
}

\author{
Aholaakko Teija-Kaisa*1 and Metsälä Eija ${ }^{2}$ \\ ${ }^{1}$ Laurea University of Applied Sciences, Vantaa, Finland \\ ${ }^{2}$ Metropolia University of Applied Sciences, Helsinki, Finland
}

\begin{abstract}
It is economically useful and ethical to improve surgical aseptic practice. A survey among OR-personnel revealed Situation-sensitivity, Reference-sensitivity, Ethicalsensitivity, and Infection-sensitivity factors for self-reported reasoning for adherence to aseptic practice recommendations. There were differences in reasoning between nurses and physicians in the pilot study. The follow-up study among nurses only revealed lack of interest and need to study more the recommendationadherence of nurses. Identifying the reasoning for recommendation- adherence it may be possible to improve outcomes of infection prevention programs.
\end{abstract}

\section{Introduction}

According to World Health Organization (WHO) [1] health care associted infections (HCAI) are the most frequent adrverse event of patients while obtaining care. The impact of HCAI implies prolonged hospital stay, long term disability, and excess deaths for the patients, and increased costs for the families. For the health-care system HCAIs imply increased resistance to antimicrobials, and massive additional financial costs. In Europe annual financial losses are estimated at approxymately $€ 7$ billion every year including direct costs only. In USA, approxymately 99000 deaths in 2002 and annual economic impact at approxymately US $\$ 6.5$ billion in 2004, were attributed to HCAIs. In low- and middle income countries surgical site infection (SSI) is the most frequent type of HAI. The rates are varying from 1.2 to 23.6 infections per 100 surgical procedures. In developed countries SSI follows after urinary tract infections and the SSI-rates vary between 1.3 and 5.2\%. In 2011 in United States [2] 4\% of acute care inpatients had at least one HCAI. The most common HCAIs were SSI (24.3\%) and pneumonia (24.3\%) with estimated numbers of 157500 each.

The Association for Profesionals in Infection Control (APIC) [3] has published a program to eliminate HCAIs. APIC aims zero tolerance. One of their goals is to influence and facilitate legistative, accreditation, and regulatory agenda for infection prevention (IP) with consumers, policy-makers, health care leaders, and perssonnel. Also WHO considers the promotion of protective measures and best practices key priorities in reducinge the burden of HCAI. Appropriate hand hygiene and correct application of precautions during invasive procedures are key components in IP. In the performance of these simple and low-cost IP-interventions staff accountability is essential. When the staff doesn't apply precautions the behavioral [1] and culture change [4] is required. In improving perioperative aseptic practice (AP) understanding of human behavior is beneficial.

\section{Background}

In SSI-prevention the role of operating room (OR) nurses is valued important. They are expected to be experts in the performance of perioperative AP to maintain surgical integrity and protect the sterile operating fields. When assessing surgical integrity, varying adherence of OR-nurses to AP-principles [5] was reported and contaminations of sterile fields were observed [6]. Breaks in AP was reported due to human behavior, lack of compliance with recommendations or adherence to infection control (IC)-procedures [6,7]. In this study we used the term "AP-adherence" when measuring the professional commitment to APrecommendations.

When improving the performance of AP it is useful to understand also the historical concepts and methods used in assessment of the IP. The concept of "compliance" was adopted from the Health Belief Model (HBM) originally developed to explain the use of health services [8] and preventive health behavior of the patient [9]. Kretzer and Larson [10] compared several models with similar constructs used in improving IC-practices. They reported wide use of traditional components of the HBM: the personal susceptibility to illness; severity of it; the benefits of recommended action/behavior; and the existence of psychological barriers such as cost, convenience, pain and embarrasment. They found out that the terms used revealed the IC-strategy behind the program. "Compliance" implies passive obedience or "giving in" to a mandate; its use may reduce internal motivation and ownership of behavior. "Improving compliance" expresses submission to a higher authority, and may cause tension in OR.

For this study we compated several previous models after founding Odgen [11] criticizing the socio-cognition models in strategies to improve recommendation adherence. She found their constructs non-specific. Like Raven [12] we considered it a practical interest to know what bases of social influence is needed to create change in human attitudes, beliefs or behavior. We found that the model of

Correspondence to: Aholaakko Teija-Kaisa, Laurea University of Applied Sciences, Vantaa, Finland; +358 468567 348, Fax +358 98868 7301: E-mail: teija-kaisa.aholaakko@laurea.fi

Received: August 18, 2016; Accepted: September 24, 2016; Published: September 28, 2016 
social powers was used in IC-programs [13-17]. High adherence to AP among nurses was reported when strategies were informative and respected the expertise of nurses. Strategies with low adherence used threats such as legal responsibility and punishment. Strategies that mediated reward, and which used others as a "frame of reference" were not very successful $[13,16]$. Nurses who felt secure in their position were likely to give information to influence others. Nurses with low self-confidence were increasing feelings of power by using a stronger basis of influence [18]. Interventions based on psychological and social principles, some similar to social powers, were reacently used in improvement of hand hygiene ${ }^{4}$. Use of real-time feed-back; shared responsibility; follow-up communication by unit-leadership for failure to correct or repeated nonadherence by any individual, regardless of role or rank; and punishment and rewards managed to improve hand hygien adherence of $78 \%$ to $97.2 \%$ in one US acute care unit.

In a study of Aholaakko [6] OR-nurses valued nonadherence to $\mathrm{AP}$ as unprofessional behaviour. In stimulated-recall interviews the OR-nurses confirmed variaton in AP and defined it as stressful. They described the stress with positive and negative feelings. Different working experience of OR-team members; time pressure; equipmentrelated problems; person-related characteristics; patient-relate challenges; varying working morals, and use of power were defined as a source of inter-professional tension and a barrier to follow APrecommendations. These results motivated us to study probable hidden factors behind AP. We aimed to explore reasoning of the self-reported adherence to surgical AP-recommendations. The research questions were: (1) what were the factors for explaining the reasoning for APadherence; 2) were there differences in reasoning for AP-adherence by gender, profession, hospital and work experience of the OR-personnel in the pilot-study, and (3) was the Reasoning for the AP-adherencescale reliable to be used among OR-nurses only.

\section{Methodology}

The scale we used fourteen statements in a self-administered questionnaire to explore the reasoning of the AP-adherence. To improve the validity of the scale we compared several theoretical models (Table 1) as a basis of the statements of the scale. Like Kretzer and Larson [10] suggested we constructed both external (environmental) and internal (personal) variables. The variables incorporated predictors of behavior introduced in the Health Belief Model by Rosenstock [8,9]: perceived susceptibility to health threats and the severity of the threat; beliefs concerning benefits of behavior without costly barriers or high risks; internal and external cues as triggers initiating the action; and selfefficacy as one's perception of one's capability of carrying out an action; subjective norms; perceived behavioral control, and intention. The scale was related also to the Social Power Model [13-16,19]: the Informational Power (three statements); Expert Power (three statements); Legitimate Power (four statements); Coercive Power (threat of punishment) (three statements); Reward Power (two statements), and Referent Power, based on identification with influencing agent (three statements). Our scale included promoting factors and barriers for AP-adherence. We used the social powers as a behavioral reference to reduce the scale potential for confusion by social desirability and attidutional bias [17]. To avoid distorted results and to improve reliability of the measurement, we measured the self-reported AP-adherence by nine positive, and five negative, four-point multi-item Likert-scaled statements, instead of single-item rankings [19].

We pre-tested the 14-item scale among 22 members of non-study OR-personnel in Helsinki University Central Hospital (HUCH)-district in 2000. Seventeen nurses and physicians answered and assessed that the scale was easy to use, and the content of it was valid. We conducted a pilot study in two ORs of HUCH between June 2000 and September 2001. We sent the hard-ware questionnaire to physicians via internal post, and to nurses by addressed envelopes in the OR. Of 285 potential first-time respondents 159 (56\%) responded. The response rate was lower among physicians (45\%) than nurses (67\%). Most respondents were female (78\%) and nurses (59\%). Most of them (72\%) had working experience in OR for more than five years. Fourty seven per cent of them had worked for more than five years in the current OR.

Before calculations we converged the variables so that the APadherence scale number 1 represented strong disagreement; 2 some disagreement; 3 some agreement; and 4 strong agreement. In the pilot study the Cronbach's alpha (a) reliability-value of the 14-item scale was moderate, 0.72 (Table 2). In the 2013 study among 70 OR-nurses only the $\alpha$-value for the overall scale was lower, $\alpha=.53$ (Table 3 ). It is congruent with previous values of Social Power-scale validation [20].

\section{Data collection}

The data of this cross-sectional study was collected in October November 2013. We sent online questionnaires only for OR-nurses in the Day Surgery Units and ORs of the two of HUCH-hospitals. Of 242 OR-nurses 73 (31\%) answered. We sent two online reminders, and nursing managers also reminded them. Questionnaires of two respondents we excluded due to missing values. Three questionnaires of graduating nurses working in the ORs we included. Of the respondents 49 (69\%) were OR-nurses, and 22 Day Surgery nurses. $45 \%$ of the responding nurses had bachelor-level education, and $45 \%$ had a working experience of 15 years or more in OR. $40 \%$ had worked in their current OR less than five years, and $21 \%$ more than 15 years. The gender was not identified due to low number of males in the study group $(\mathrm{n}=14)$.

\section{Data analysis}

Firstly, we used descriptive statistics, frequencies and meanvalues, to describe the charasteristics of the 2013 study participants. Secondly, by using Principal Component Analysis (PCA) we explored the most meaningful reduction of 14 items explaining the reasoning for AP-adherence in the pilot-study data with reasonable number of respondents. The four factors, 1) Situation-sensitivity; 2) Referencesensitivity; 3) Ethical-sensitivity; and 4) Infection-sensitivity explained more than $64 \%$ of the total variance in reasoning the AP-adherence (Table 2).

Thirdly, we constructed summation variables according to the four pilot study factors for further analysis using the current data. Means were chosen instead of sums because of the varying numbers of items. We identified the reasoning for AP-adherence by the highest factor score of each individual respondent of the pilot study. We tested differences in reasoning for AP-adherence by independent sample $t$-tests to discover differences according to gender, profession and work experience. The homogenity of variances was not reached in every $t$-test. The results of the independent sample $t$-tests were introduced according to Levine's test with pooled or equal variances. $p<0.05$ was considered statistically significant. Due to the varying Cronbach's $\alpha$-values and small response-rate further analyses to study differences according to backgroung factors were not conducted in 2013.

\section{Ethics}

We aimed performing good ethical practice, privacy, and respect of 
Table 1. The structure of the Reasoning for the Aseptic Practice Adherence-scale.

\begin{tabular}{|c|c|}
\hline $\begin{array}{l}\text { Items measuring the adherence to } \\
\text { Aseptic Practice (AP) in surgery }\end{array}$ & References \\
\hline "I perform AP because: & AP promoting factors \\
\hline I consider AP as rewarding" & $\begin{array}{l}\text { Reward Power (Raven 2008) } \\
\text { Subjective norm, professional trigger (Kretzer \& Larsen 1998, Killen 2002) } \\
\text { Adherence to recommendations (Becker } \text { et al. 1990, Flin et al.2006) }\end{array}$ \\
\hline also the others perform AP" & $\begin{array}{l}\text { Referent Power (Raven 2008) } \\
\text { Perceived behavioral control (Kretzer \& Larsen 1998) } \\
\text { The peer influence (Becker et al. 1990, Zimakkoff et al. 1992) }\end{array}$ \\
\hline I want to practice like an expert" & $\begin{array}{l}\text { Referent Power / Expert Power (Raven 2008) } \\
\text { Subjective norms (Kretzer \& Larsen 1998) } \\
\text { Intention as a cue (Kretzer \& Larsen 1998) } \\
\text { Perceived behavioral control (Kretzer \& Larsen 1998) } \\
\text { Ethical responsibility (Killen 2002) }\end{array}$ \\
\hline I know it as a right thing to do" & $\begin{array}{l}\text { Legitimate Power / Reward Power (Raven 2008) } \\
\text { Subjective norms (Kretzer \& Larsen 1998) } \\
\text { Ethical responsibility (Killen 2002) } \\
\text { Adherence to recommendations (Becker et al. 1990, Flin et al.2006) }\end{array}$ \\
\hline the patient has right to good care" & $\begin{array}{l}\text { Legitimate Power / Expert Power (Raven 2008) } \\
\text { Subjective norms (Kretzer\& Larsen 1998) } \\
\text { Ethical responsibility (Killen 2002) }\end{array}$ \\
\hline I have the legal responsibility to do so" & $\begin{array}{l}\text { Legitimate Power (Raven et al. 1998, Raven 2008) } \\
\text { Self-efficacy (Kretzer \& Larsen 1998) } \\
\text { Perceived behavioral control (Kretzer \& Larsen 1998) }\end{array}$ \\
\hline I am afraid of becoming in responsible for surgical site infection" & $\begin{array}{l}\text { Legitimate Power / Coersive Power (Raven 2008, Raven et al. 1998) } \\
\text { Self-efficacy (Kretzer \& Larsen 1998) } \\
\text { Perceived behavioral control (Kretzer \& Larsen 1998) }\end{array}$ \\
\hline I am afraid of getting a health care related infection" & $\begin{array}{l}\text { Informative Power (Raven 2008) } \\
\text { Perceived health threat (Kretzer \& Larsen 1998) } \\
\text { Susceptibility (Rosenstock 1974) } \\
\text { Awareness of patient having AIDS (Becker et al. 1990) }\end{array}$ \\
\hline every patient is a potential carrier of blood born infection" & $\begin{array}{l}\text { Informative Power (Raven 2008) } \\
\text { Perceived health threat (Kretzer \& Larsen 1998) } \\
\text { Susceptibility (Rosenstock 1974) } \\
\text { Awareness of patient having AIDS (Becker } \text { et al. 1990) }\end{array}$ \\
\hline "I am not performing AP, because & AP barriers \\
\hline I forget to observe my own AP" \# & $\begin{array}{l}\text { Referent Power (Raven 2008) } \\
\text { Adherence to recommendations (Becker } \text { et al. 1990, Flin et al.2006) }\end{array}$ \\
\hline the operating schedules in my department are too busy" \# & $\begin{array}{l}\text { Coersive Power (Raven 2008) } \\
\text { Time as an AP- barrier (Becker et al. 1990, Zimakoff et al. 1992, Kretzer \& Larsen 1998, Killen 2002, Espin \& } \\
\text { Lingard 2001, Aholaakko 2011) } \\
\text { Self-efficacy (Kretzer \& Larsen } 199\end{array}$ \\
\hline I am too slow" \# & $\begin{array}{l}\text { Coersive Power (Raven 2008) } \\
\text { Time as an AP-barrier (Kretzer \& Larsen 1998, Aholaakko 2011) } \\
\text { Self-efficacy (Kretzer \& Larsen 1998) }\end{array}$ \\
\hline I don't dare to interfere in other's AP" \# & $\begin{array}{l}\text { Expert Power (Raven 2008), } \\
\text { Convenience (Rosenstock 1974) } \\
\text { Self-efficacy (Kretzer \& Larsen 1998) }\end{array}$ \\
\hline the research findings do not support the importance of AP as SSI-risk" \# & $\begin{array}{l}\text { Informational Power (Raven 2008) } \\
\text { Perceived health threat (Kretzer \& Larsen 1998) } \\
\text { Awareness of patient having AIDS (Becker } \text { et al. } 1990\end{array}$ \\
\hline
\end{tabular}

\#) Items were converted in the analysis: 1 is 4 in Likert scale.

the rights of respondents for this study. Acceptance for this survey was given by the Heads of Departments of Medicine and Nursing in two hospitals of $\mathrm{HUCH}$. We informed nurses and physicians in meetings, and physicians also via e-mail. Final information we gave in a survey covering letter. We received the consent in the form of returned questionnaires.

\section{Findings}

In the pilot study (Table 2) we found that the PCA defined $64 \%$ of the variance for reasoning for AP-adherence in the OR. The Situationsensitivity factor covered $18.6 \%$, Reference-sensitivity $18.1 \%$, Ethicalsensitivity $16.5 \%$, and Infection-sensitivity $10.5 \%$ of the explained variance. The highest mean value of 14 items was in the statement "patient having the right to good care" (3.91). Two mean values of $<3$ were found when the threat was measured by the items "fear of getting an occupational infection" (2.40) and "fear of being responsible for surgical site infection" (2.41).

In the pilot study the highest factor score of PCA revealed that $32 \%$ of respondents were Situation-sensitive $(\mathrm{n}=47), 32 \%$ Reference-sensitive $(\mathrm{n}=47), 19 \%$ Infection-sensitive $(\mathrm{n}=27)$ and $17 \%$ Ethical-sensitive $(\mathrm{n}=24)$ by their reasoning for AP-adherence. In the pilot study we compared differences in reasoning for AP-adherence by independent sample $t$-tests of background factors (Research question 2). The $t$-tests elicited statistically significant differences only among Ethical-sensitive reasoning for AP between physicians and nurses. Nurses (mean 3.90, SD .23), were more Ethical-sensitive than physicians (mean 3.66, SD .58). The difference was statistically significant $(t=-3.19, \mathrm{p}=0.002)$. 
In the pilot study we measured moderate reliability of the constructed scale $(\alpha=0.72)$ among registered OR-personnel $(n=145)$. Deletion of the item mearuring time-pressure as a barrier for AP would increase the $\alpha$-value up to 0.73 . Among phycisans $(n=56)$ the $\alpha$-value was 0.78 . Deletion of item "existence of evidence concerning AP as SSIrisk" would increase it to 0.79 and deletion of the item "experience of not too busy operates schedules" to 0.79 . Among pilot-study nurses $(n=89)$ the reliability of the whole scale was 0.67 . Deletion of the item "willing to practice like an expert" would increase it to 0.68 and deletion of the converted item describing to "forget observing one's own AP" to 0.674 .

In 2013, among OR-nurses only, the whole scale reliability was 0.53 . The $\alpha$-values for scales constructed according to the four factors were between 0.54 and 0.77 . Deleting the item "also other performing AP" would increase the scale reliability to 0.56 . Deleting converted item of "evidence not supporting the AP as an SSI-risk factor" would increase it, to 0.56 and an item defining busy operating schedules as AP-barriers would increase the reliability to 0.53 (Table 3 ).

\section{Discussion}

We found that the results of this study supported the earlier conclusions that the factors related to AP-adherence are not clear $[10,13]$. In the pilot study we constructed a scale for reasoning the AP-adherence. By using it we found differences between nurses and physicians only in ethical reasoning of the AP-adherence. We wanted to test the scale among nurses only in the 2013. Due to the low response rate this study was not able to answer to the research question 2: was the Reasoning for the AP-adherence-scale realible to be used among OR-nurses only.

Previous trials to test reasoning for the AP-adherence according to socio-cognitive models encouraged us to use methods without direct background theory [10-12]. We aimed to reach the conceptual validity of the questionnaire by using acceptable and logical items guided by the literature. Clinical professional accepted the questions during the pre- and pilot-studies.

In the pilot-study we used the PCA to construct a logical model having the maximal amount of inter-item correlation of the original variables. Analysis reduced the reasoning for AP-adherence to four factors. All items we used in the analysis were well loaded to the four components. The covering effect of almost $64 \%$ of these components is a good result. The variances of Situation-sensitivity, Referencesensitivity and Ethical-sensitivity were almost equal. Variance of Infection-sensitive reasoning was lower. This may reflect that the OR is considered as an environment in which the personnel is familiar with the potential daily risk to "obtain" or "cause" an infection. It may be that few OR professionals considered the infection risk as a severe personal threat. These findings give limited support to the assumptions of the Health Belief Model [8,9] and findings of Kretzer and Larson [10].

We named the factors describing the different types of reasoning for AP-adherence as "sensitivities" from the content point of view. The

Table 2. The Adherence to Surgical Aseptic Practice Factor Composition in the pilot study

\begin{tabular}{|c|c|c|c|c|c|c|c|}
\hline & \multirow[t]{2}{*}{ Mean (SD) } & \multicolumn{4}{|c|}{ Factor loading values } & \multirow[t]{2}{*}{ Communalities } & \multirow{2}{*}{$\begin{array}{c}\text { Cronbach's } \\
\alpha \text { reliability } \\
\text { coefficient }\end{array}$} \\
\hline & & $\begin{array}{l}\text { Situation- } \\
\text { sensitivity }\end{array}$ & $\begin{array}{l}\text { Reference- } \\
\text { sensitivity }\end{array}$ & $\begin{array}{c}\text { Ethical- } \\
\text { sensitivity }\end{array}$ & $\begin{array}{l}\text { Infection- } \\
\text { sensitivity }\end{array}$ & & \\
\hline Situation-sensitivity & & & & & & & .75 \\
\hline Interfering in other's AP & $3.54(0.65)$ & 0.86 & & & & 0.74 & \\
\hline Experience of not too busy operating schedules ${ }^{\#}$ & $3.39(0.81)$ & 0.78 & & & & 0.63 & \\
\hline Experience of not being slow at work ${ }^{\#}$ & $3.73(0.50)$ & 0.71 & & & & 0.58 & \\
\hline Existence of evidence concerning AP as SSI-risk ${ }^{\#}$ & $3.74(0.52)$ & 0.67 & & & & 0.61 & \\
\hline Observing one's own $\mathrm{AP}^{\#}$ & $3.50(0.76)$ & 0.53 & & & & 0.48 & \\
\hline Reference-sensitivity & & & & & & & .71 \\
\hline Experiencing legal responsibility for AP & $3.16(0.96)$ & & 0.77 & & & 0.62 & \\
\hline Experiencing AP as rewarding & $3.03(1.05)$ & & 0.74 & & & 0.73 & \\
\hline Experiencing also others performing AP & $2.37(1.04)$ & & 0.67 & & & 0.48 & \\
\hline Ethical-sensitivity & & & & & & & .69 \\
\hline Knowing AP as right thing to do & $3.85(0.43)$ & & & 0.78 & & 0.64 & \\
\hline Willing to practice like an expert & $3.64(0.72)$ & & & 0.75 & & 0.73 & \\
\hline Experiencing patient having right to good care & $3.91(0.41)$ & & & 0.72 & & 0.60 & \\
\hline $\begin{array}{l}\text { Infection-sensitivity } \\
\text { Fear of being in responsible for patient's SSI }\end{array}$ & $2.46(0.99)$ & & $(0.68)$ & & 0.50 & 0.71 & .70 \\
\hline Fear of getting an occupational infection & $2.40(0.97)$ & & $(0.58)$ & & 0.54 & 0.63 & \\
\hline Fear of every patient being a potential carrier of BBI & $3.55(0.76)$ & & & & 0.74 & 0.73 & \\
\hline Eigenvalue & & 3.38 & 2.74 & 1.69 & 1.11 & & \\
\hline Percent of explained variance & & 18.64 & 18.10 & 16.46 & 10.48 & & \\
\hline Cumulative \% of Variance & & 18.64 & 36.75 & 53.20 & 63.69 & & \\
\hline Total Scale & & & & & & & .725 \\
\hline
\end{tabular}

$\mathrm{AP}=$ aseptic practice, $\mathrm{SSI}=$ surgical site infection, $\mathrm{BBI}=$ blood born infection; \#) Item converted as positive: 1 is 4 in Likert scale 
Table 3. Reliability for Reasoning for Adherence to Surgical Aseptic Practice-Scale.

\begin{tabular}{|c|c|c|c|c|c|c|c|c|}
\hline \multirow[t]{2}{*}{ Factor } & \multicolumn{4}{|c|}{ Pilot-study } & \multicolumn{4}{|c|}{ Study in 2013} \\
\hline & $\begin{array}{c}\text { Mean (SD) } \\
n=146\end{array}$ & $\begin{array}{c}\text { Scale reliability } \\
\alpha=\end{array}$ & $\begin{array}{c}\text { Sub-scale } \\
\alpha \text { if item } \\
\text { deleted }\end{array}$ & $\begin{array}{c}\text { Total scale } \\
\alpha \text { if item } \\
\text { deleted }\end{array}$ & $\begin{array}{c}\text { Mean (SD) } \\
n=71\end{array}$ & $\begin{array}{c}\text { Scale } \\
\text { reliability } \\
\alpha=\end{array}$ & $\begin{array}{l}\text { Sub-scale } \alpha \text { if } \\
\text { item deleted }\end{array}$ & $\begin{array}{c}\text { Total scale } \\
\alpha \text { if item } \\
\text { deleted }\end{array}$ \\
\hline Situation-sensitivity & & .747 & & & & .770 & & \\
\hline Willingness to interfere in other's $\mathrm{AP}^{\#}$ & $3.54(0.65)$ & & .654 & .720 & $3.63(.594)$ & & .727 & .501 \\
\hline $\begin{array}{l}\text { Experience of not too busy operating } \\
\text { schedules } \#\end{array}$ & $3.39(0.81)$ & & .687 & .735 & $3.37(.945)$ & & .658 & .531 \\
\hline Experience of not being slow at work ${ }^{\#}$ & $3.73(0.50)$ & & .712 & .721 & $3.66(.759)$ & & .678 & .518 \\
\hline $\begin{array}{l}\text { Existence of evidence concerning AP as } \\
\text { SSI-risk }^{\#}\end{array}$ & $3.74(0.52)$ & & .711 & .725 & $3.96(.204)$ & & .817 & .535 \\
\hline Observing one's own $\mathrm{AP}^{\#}$ & $3.50(0.76)$ & & .743 & .715 & $3.61(.687)$ & & .690 & .487 \\
\hline Reference-sensitivity & & .712 & & & & .543 & & \\
\hline Experience of legal responsibility for AP & $3.16(0.96)$ & & .603 & .691 & $3.67(.583)$ & & .546 & .498 \\
\hline Experiencing AP as rewarding thing to do & $3.03(1.05)$ & & .554 & .692 & $3.41(.940)$ & & .288 & .485 \\
\hline Experiencing also others performing AP & $2.37(1.04)$ & & .702 & .702 & $2.57(1.111)$ & & .429 & .559 \\
\hline Ethical-sensitivity & & .695 & & & & .626 & & \\
\hline Knowing AP as right thing to do & $3.85(0.43)$ & & .557 & .714 & $3.96(.204)$ & & .568 & .515 \\
\hline Willing to practice like an expert & $3.64(0.72)$ & & .662 & .702 & $3.94(.232)$ & & .663 & .510 \\
\hline $\begin{array}{l}\text { Experiencing patient having right to good } \\
\text { care }\end{array}$ & $3.91(0.41)$ & & .615 & .710 & $3.99(.122)$ & & .399 & .524 \\
\hline Infection-sensitivity & & .700 & & & & .621 & & \\
\hline Fear of being in responsible for SSI & $2.46(0.99)$ & & .522 & .697 & $2.74(.958)$ & & .276 & .479 \\
\hline Fear of getting an occupational infection & $2.40(0.97)$ & & .457 & .700 & $2.77(.995)$ & & .317 & .477 \\
\hline $\begin{array}{l}\text { Fear of patient being a potential carrier of } \\
\text { BBI }\end{array}$ & $3.55(0.76)$ & & .765 & .703 & $3.83(.380)$ & & .718 & .501 \\
\hline $\begin{array}{l}\text { Reasoning for Adherence to Surgical } \\
\text { Aseptic Practice-Scale with } 14 \text { items } \\
\text { Cronbach's } \alpha \text {-reliability coefficient }\end{array}$ & & .725 & & & & .528 & & \\
\hline
\end{tabular}

$\mathrm{AP}=$ aseptic practice, $\mathrm{SSI}=$ surgical site infection, $\mathrm{BBI}=$ blood born infection; \#) Item converted as positive: 1 is 4 in Likert scale.

names were obvious except the name for Situation-sensitivity factor. It was initially named "Stress-sensitivity", then as "Stress-insensitivity". After closer inspection, the focus of reasoning was found also from the results of the previous qualitative study [6]. According to these results the OR-nurses reduced their moral-related stress also by withdrawal AP. The membership categories revealed the loose moral of surgeons and nursing colleagues, but also the importance of "patient's best" as a practical value guiding the surgical AP.

According to Killen [21] the moral motivation, moral character, characteristics of the institutional unit, competence level, and the ethical ideology of the nurse are components of the "model of morality in perioperative nursing". The model premises state, that the moral motivation and moral character relate directly to moral action in nursing and the outcomes of patient care. Our findings support both these findings and the discussion of Raven [15] in which he considered it a practical interest to know what bases of social influence is needed to create change in human attitudes, believes or behavior.

The importance of Ethical-sensitivity in reasoning for APadherence were not supported by studies in which the Social Power Model was used [14,17]. Also the findings of our qualitative research in the study OR [6] made visible the multi-dimensionality of AP-adherence and supported the use of factor loadings. By factor loadings we typed $32 \%$ of respondents' situation-sensitive, 32\% reference-sensitive, $19 \%$ infection-sensitive, and $17 \%$ ethical-sensitive. Statistically significant differences which appeared within ethical-sensitivity by profession in the pilot-study, and the lower reliability-values of nurses in both measurements will be important to recognize in discussion concerning profession- and position-related decision making in AP. This was supported by previous studies [6,11].
We found differences in reasoning for AP-adherence by background factors only in Ethical-sensitivity in the pilot-study. This may be due to the high number of experienced OR practitioners in the study group. According to our initial findings gender and work experience were not related to the reasoning for AP-adherence. Killen [21] noted that $85 \%$ of perioperative nurses had less than five years experience and $22 \%$ identified themselves as an "expert nurse". In our pilot-study, $72 \%$ of respondents had been working in the OR department for more than five years and ethical-sensitivity explained $17 \%$ of the reasoning for AP adherence by factor loadings.

These findings support also the findings of our qualitative study [6] in which the supervising nurses used constructive means; they did not turn the "surgical field into a battle field", but instead they did not interfere in other's AP for the best of the surgical patient. The role of Ethical-sensitivity is a multi-dimensional issue in situations like this. The non-interference in AP is possible to define as an error from IC point of view, and as a desired behavior from the ethical point of view.

Earlier the AP-performance was found to be a source of interprofessional tension in the OR [6,21]. According to Beauchamp and Childress [22] tension may arise from conflicts over professional standards, conflicts between professional commitments, or commitments of people outside the profession. Disagreement can also emerge about appropriate forms of balancing AP, a genuine dilemma in AP, and insufficient information or evidence regarding IP. We hope that despite of the unanswered questions due to the low response-rate in 2013 these findings would be useful in progressing the assessment of AP-adherence. 


\section{Study limitations}

Initially we attempted to measure the reasoning for adherence to AP among nurses only in 2013. The low level of participation provided many challenges to this study. Possibly this indicated not only the disappeared impact of our previous AP-development, but also the missing professional need for participating in the AP-improvement among the study OR-nurses.

The low level of participation made us difficult to study APadherence both as a multi-professional and a nursing specific intervention. This jeopardized reliable assessment of results. This can be seen in the results of PCA exploring AP among the whole OR-personnel, and also from the $t$-tests comparing the gender- and profession-related AP-adherence in the pilot-study. Also the results of reliability analyses in 2013 are challenging to discuss. Cronbach $\alpha$-values for the four scales of reasoning factors for AP-adherence were quite good in the pilot-survey. In 2013 the values measured among nurses only, were low.

We made compromises for two factors, Infection-sensitivity and Reference-sensitivity, at the cost of the $\alpha$-value, to create meaningful summation variables. This may be one of the critical points of this study for further development. Retesting of the factors in larger, more controlled study groups may justify these scales as variables identifying the reasoning for AP-adherence. The sampling limitations of this study do not justify conclusions concerning the stability, and profession specificity of the reasoning for AP-adherence. The possibility to generalize the old results, and the results of the recent survey among nurses only, is limited to the respondents only.

The objectivity of self-assessment we used to measure APadherence is limited. According to Evans et al. [23] external validation by observation or participating data collection methods are needed with self-assessment. In this study, we used the previous studies [921,24-27] and the qualitative findings in the study OR [6] to increase the objectivity of the self-assessment measurements, and to support the methodological choises.

\section{Recommendations for clinical practice, education and future research}

AP is an intervention during which the morals of the individual practitioner and the shared morals of the OR-team are challenged by various internal and external issues [6]. Our findings revealed the need to study more closely the perioperative AP in OR. The professional practice encountered during this program was also supported by other studies $[4,5,13,17]$ in which professional strategies were combined with AP-adherence. In the future these findings should be tested more closely, specially when the Ethical-sensitivity is considered a criterion for an expert nurse.

In clinical practice, OR-nurses are mainly responsible for AP when establishing and disestablishing the sterile field. All members of OR personnel are responsible for maintaining it. AP-adherence should therefore be discussed, agreed and evaluated according to the practice of the entire OR-team ${ }^{6}$ supervised and coordinated by OR nurses.

Identification of individual reasoning for AP-adherence may increase understanding of professional commitments, demands and challenges in performance of AP and during IP-programs. The situation, context, and culturally specific issues of surgical APadherence should be studied more closely. The power of expertise, differences in education and the attitudes of using the evidence based knowledge in OR may also merit further study. We recommend that the surgical IP-education should be carefully planned and based on the consideration of behavioral evidence and experiences reported by ORpersonnel.

\section{Conclusion}

We identified four factors: Situation-sensitivity; Referencesensitivity; Ethical-sensitivity; and Infection-sensitivity, related to selfreported reasoning for AP-adherence. They may possibly reveal the personal ways to reason the $\mathrm{AP}$-adherence. In strengthening positive attitudes toward AP, and reinforcing the conviction that each individual can influence group behavior in IP, it would be useful to identify the individual sensitivities to AP-recommendations. This could support participation in IP and progress AP-adherence of all personnel. Reflection and feedback concerning AP could be easier when the ORpersonnel pay attention to the effect they have on the feelings and needs of others. We recommend that by using constructive means, and by avoiding AP-related stress it might be possible to decrease the need for situation- and reference-sensitive reasoning for $\mathrm{AP}$, and replace it with evience based and ethical reasoning.

\section{References}

1. World Health Organization (2011) Report on the Burden of Endemic Health CareAssociated Infection World Wide. Systematic review of the literature.

2. Magill SS, Edwards JR, Bamberg W, Beldavs ZG, Dumyati G, et al. (2014) Multistate Point-Prevalence Survey of Health Care-Associated Infections. $N$ Engl J Med 370: 1198-1208. [Crossref]

3. [No authors listed] (2012) APIC strategic plan 2020. Am J Infect Control 40: 391 [Crossref]

4. Cumbler E, Castillo L, Satorie L, Ford D, Hagman J, et al. (2013) Culture Change in Infection Control. Applying Psychological Principles to Improve Hand Hygien. J Nurs Care Qual 28: 304-311. [Crossref]

5. Adams JS, Korniewicz DM, El-Masri MM (2011) A descriptive study exploring the principles of asepsis techniques among perioperative personnel during surgery. CORNJ 29: 6-24. [Crossref]

6. Aholaakko TK (2011) Reducing surgical nurses' aseptic practice-related stress. J Clin Nurs 20: 3339-3350. [Crossref]

7. Hopper WR, Moss R (2010) Common breaks in sterile technique: clinical perspectives and perioperative implications. AORN J 91: 350-364. [Crossref]

8. Rosenstock IM (1966) Why people use health services. Milbank Mem Fund Q 44 Suppl: 94-127. [Crossref]

9. Rosenstock IM (1974) Historical Origins of the Health Belief Model. Health Education Monographies 2: 1-8.

10. Kretzer EK, Larson EL (1998) Behavioral interventions to improve infection control practices. Am J Infect Control 26: 245-253. [Crossref]

11. Ogden J (2003) Some problems with social cognition models: a pragmatic and conceptual analysis. Health Psychol 22: 424-428. [Crossref]

12. Raven BH (2008) The Bases of power and the Power/Interaction Model of Interpersonal Influence. Analyses of Social Issues and Public Policy. 8: 1-22.

13. Seto WH, Ong SG, Ching TY, Ng SH, Chu YB, et al. (1990) Brief report: the utilization of influencing tactics for the implementation of infection control policies. Infect Control Hosp Epidemiol 11: 144-150. [Crossref]

14. Seto WH (1995) Staff compliance with infection control practices: application of behavioural sciences. J Hosp Infect 30 Suppl: 107-115. [Crossref]

15. Podsakoff PM, Schriesheim CA (1985) Field Studies of French and Raven's Basesof Power: Critique, Reanalysis, and Suggestions for Future Research. Psychological Bulletin 97: 387-411.

16. Seto WH, Ching TY, Yuen KY, Chu YB, Seto WL (1991) The enhancement of infection control in-service education by ward opinion leaders. Am J Infect Control 19: 86-91. [Crossref]

17. Raven BH, Haley RW (1982) Social influence and compliance of hospital nurses with 
infection control policies. In Social psychology and behavioral medicine (Eiser JR ed.) John Wiley \& Sons Ltd, Chichester 413-438.

18. Schriesheim CA, Hinkin TR, Podsakoff PM (1991) Can Ipsative and Single-Item Measures Produce Erroneous Results in Field Research in field Studies of French and Raven's (1959) Five Bases of Power? An Empirical Investication. Journal of Applied Psychology 76: 106-114.

19. Nesler MS, Aquinis H, Quigley BM, Lee S-J, Tedeschi JT (1999) The Development and Validation of a Scale Measuring Global Social Power Based on French and Raven's Power Taxonomy. Journal of Applied Social Psychology 29: 750-771.

20. Killen AR (2002) Stories from the operating room: moral dilemmas for nurses. Nurs Ethics 9: 405-415. [Crossref]

21. Beauchamps TL, Childress JF (2001) Nonmaleficance. In Principles of biomedical ethics (Beauchamps TL, Childress JF ed.) 5th edn, Oxford University Press, New York, 113-164.
22. Evans AW, McKenna C, Oliver M (2002) Self-assessment in medical practice. J R Soc Med 95: 511-513. [Crossref]

23. Becker MH, Janz NK, Band J, Bartley J, Snyder MB, et al. (1990) Noncompliance with Universal Precautions Policy: why do physicians and nurses recap needles? Am J Infect Control 18: 232-239. [Crossref]

24. Flin R, Yule S, McKenzie L, Paterson-Brown S, Maran N (2006) Attitudes to teamwork and safety in the operating theatre. Surgeon 4: 145-151. [Crossref]

25. Zimakoff J, Kjelsberg AB, Larsen SO, Holstein B (1992) A multicenter questionnaire investigation of attitudes toward hand hygiene, assessed by the staff in fifteen hospitals in Denmark and Norway. AJIC 20: 58-64. [Crossref]

26. Espin SL, Lingard LA (2001) Time as a catalyst for tension in nurse-surgeon communication. AORN J 74: 672-682. [Crossref]

Copyright: $@ 2016$ Teija-Kaisa A. This is an open-access article distributed under the terms of the Creative Commons Attribution License, which permits unrestricted use, distribution, and reproduction in any medium, provided the original author and source are credited. 